\title{
ANALYSIS OF ERODED \\ TI-6AL-4V SINGLE CRATERS AND SURFACES IN OIL BY ELECTRON MICROSCOPY AND OPTICAL EMISSON SPECTROSCOPY
}

\section{Conference Paper}

\section{Author(s):}

Wiessner, Moritz; Martendal, Caroline P.; Borges Esteves, Paulo M.; Kunze, Karsten (D); Wegener, Konrad

Publication date:

2019-10-23

Permanent link:

https://doi.org/10.3929/ethz-b-000407033

Rights / license:

In Copyright - Non-Commercial Use Permitted 


\section{COB-2019-0836}

\section{ANAL YSIS OF ERODED TI-6AL-4V SINGLE CRATERS AND SURFACES IN OIL BY ELECTRON MICROSCOPY AND OPTICAL EMISSON SPECTROSCOPY}

\section{Moritz Wiessner}

ETH Zürich, Institute of Machine Tools and Manufacturing, Leonhardstrasse 21, 8092 Zürich, Switzerland wiessner@iwf.mavt.ethz.ch

\section{Caroline Pereira Martendal}

Federal University of Santa Catarina, Campus Universitario, 88.040-900 Florianopolis (SC), Brazil

caroline.pm@posgrad.ufsc.br

\section{Paulo Borges Esteves}

ETH Zürich, Institute of Machine Tools and Manufacturing, Leonhardstrasse 21, 8092 Zürich, Switzerland bpaulo@student.ethz.ch

\section{Karsten Kunze}

ETH Zürich, Scientific Center for Optical and Electron Microscopy (ScopeM), Otto-Stern-Weg 3, 8093 Zürich, Switzerland karsten.kunze@scopem.ethz.ch

\section{Konrad Wegener}

ETH Zürich, Institute of Machine Tools and Manufacturing, Leonhardstrasse 21, 8092 Zürich, Switzerland wegener@iwf.mavt.ethz.ch

Abstract. The comprehension of the metallurgical transformations of the workpiece can contribute with valuable data for simulation models and for a better understanding of surface creation in electrical discharge machining (EDM). This is necessary to improve the process in the scope of zero defect manufacturing. This work aims to investigate the influence of EDM on the often used but difficult to machine alloy Ti-6Al-4V. Single and multiple sparks in oil are performed and subsequently analyzed with advanced electron microscopy methods and optical high-speed emission spectroscopy. The microscopic analysis of recast layer and heat affected zones in addition to the plasma analyses provides deep insight into the process and contributes with new information about EDM. Results showed that, with the employed machining conditions, phase transformations occur at the surface of the material. Also, a superficial carbide layer was observed exclusively during multi sparks experiments. The performed analyses of metallurgical and topographic aspects of EDM describe its surface integrity, i.e., the condition of a surface generated by this manufacturing process. The emission spectroscopy analysis shows that the erosion plasma consists mostly of the dielectric elements with a high amount of hydrogen, which comes from the breaking of the dielectric hydro-carbon chains. This spectrum suggests the plasma takes part in the formation of the carbide layer.

Keywords: Surface Integrity; EDM; Phase Transformation; Heat-affected Zones, Optical Emission Spectroscopy

\section{INTRODUCTION}

The demand for more precise and complex parts is worldwide growing. The aero-space market is one example where defective parts are not tolerated and rejects are costly. Electrical discharge machining (EDM) is one of the key technologies in those markets. The high precision comes with some drawbacks as long machining times and often a heat-affected zone on the surface of the parts. The analysis of ED-machined surfaces and heat-affected zones are key factors to understand the formation of surface defects and surface transformation. Also selection of the tool material is important, in case of TI-6AL-4V differences in crack density and recast layer thickness are observed (Hasçalık and Çaydaş, 2007). Machine monitoring for zero-defect manufacturing becomes more and more important (Caggiano et al., 2015), therefore the understanding of defects is a crucial factor for creating new technologies and methods. Further important data and basic understanding can be gathered to develop more sophisticated process models. Normal analysis methods like the analysis of the recast layer with light microscopy are not enough for a full scope. A deeper insight can be provided by scanning electron microscopy (SEM) and the imaging methods of secondary electrons (SE), 
backscattered electrons (BSE), energy dispersive X-ray spectroscopy (EDX), and electron backscatter diffraction (EBSD) (Klocke et al., 2016). An important role for the formation of the surface is also taken by the dielectric and the polarity (Holsten et al., 2018). Plasma spectroscopy during erosion provides an insight into the erosion process from a different angle like the tool workpiece interaction (Macedo, 2018). Especially interesting is the atmosphere respectively the plasma interacting with the molten material.

\section{MATERIALS AND METHODS}

The machining of the workpieces is conducted in an AgieCharmilles FORM 1000 die-sinking EDM machine, using hydrocarbon oil Oelheld IME 110 as dielectric medium. A $32 \mu$ s rectangular shaped transistor discharge is chosen with an electric current of $20 \mathrm{~A}$, an open voltage of $250 \mathrm{~V}$ and a negative copper tool polarity. Single craters are performed with a conically shaped tip electrode and the surface with multiple craters with a 3 by $3 \mathrm{~mm}$ squared electrode. A planar workpiece electrode from titanium alloy Ti-6Al-4V is used. For the metallurgical analysis by SEM a FEI Quanta $200 \mathrm{~F}$ is employed. Cross sections of the sample were prepared perpendicular to the eroded polished surface with a broad ion beam (BIB) milling on a Hitachi IM 4000, visualized in Figure 1 A and B.

A

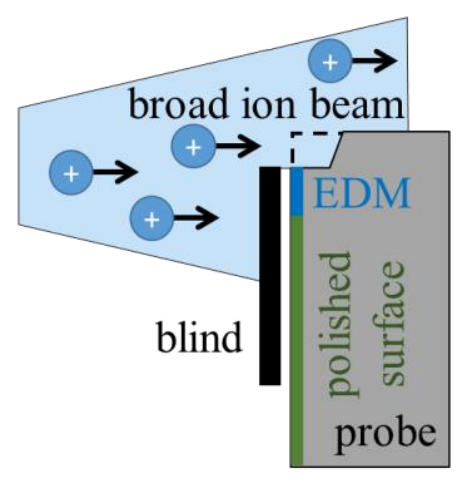

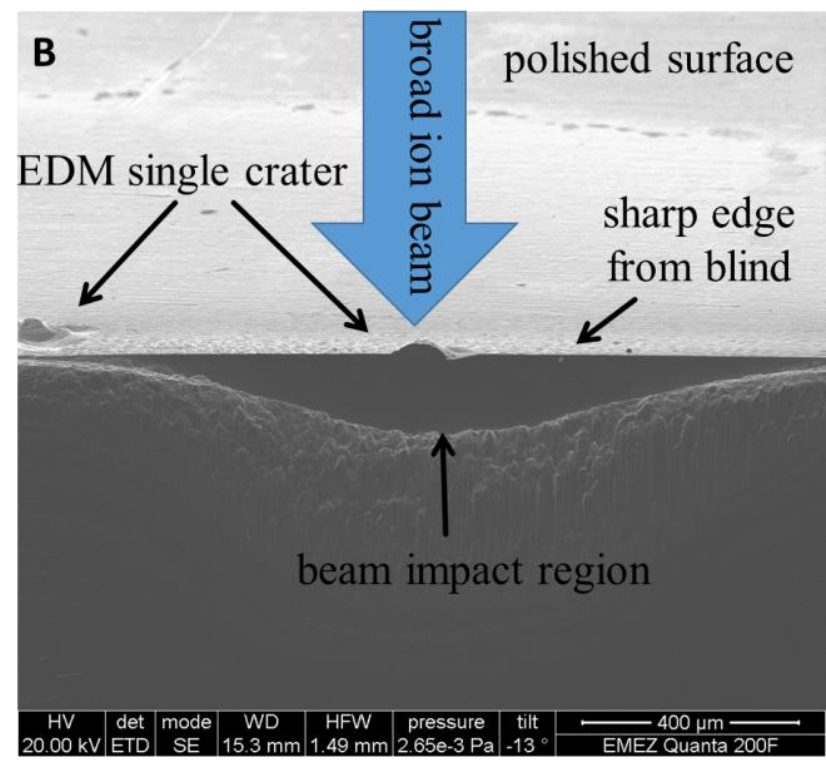

Figure 1. A: Schematic of broad ion beam probe preparation B: SEM image of the processed sample

An Acton Research Spectrograph SP2556 connected to a Vision Research Phantom V12.1 high-speed camera is used for optical emission spectroscopy. A bundle of $\varnothing 100 \mu \mathrm{m}$ optical fibers collects the plasma light emission. An oscilloscope is used to observe the current and voltage signals and triggers the high-speed camera, seen in Figure 2.

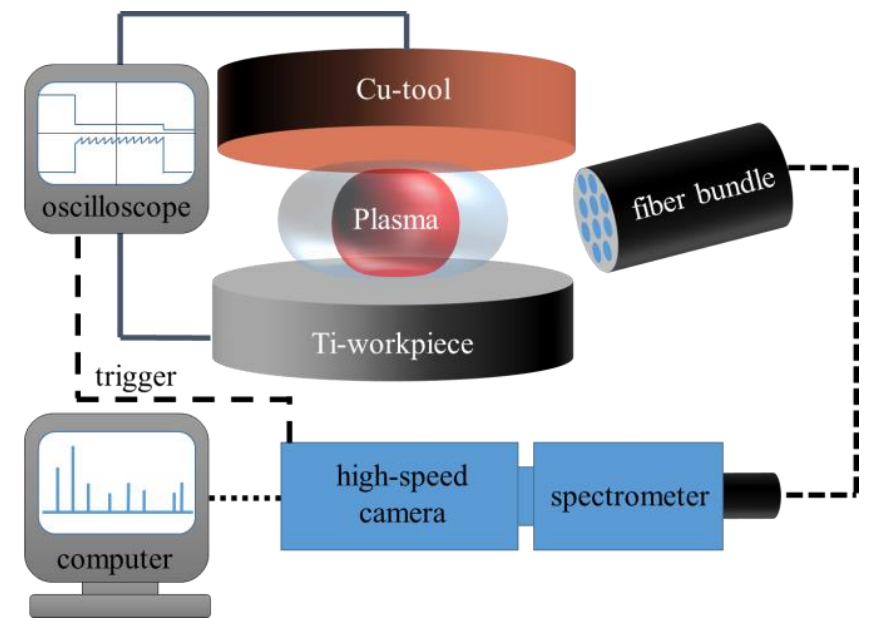

Figure 2. Setup up for optical emission spectroscopy 


\section{RESULTS}

Since EDM is a stochastic process, one single crater cannot be representative for all discharges, nevertheless the analysis of single craters already gives a deep insight into the EDM process. The presented cross section of a Ti-6Al-4V single crater seen in Figure 3 shows several regions of interest. Two different zones can be identified in Figure 3 B: an eroded region, whose maximal depth at the cross section is $10 \mu \mathrm{m}$, and a built-up zone, whose highest point from the surface measures $18 \mu \mathrm{m}$. Crater diameter in this section is $154 \mu \mathrm{m}$.

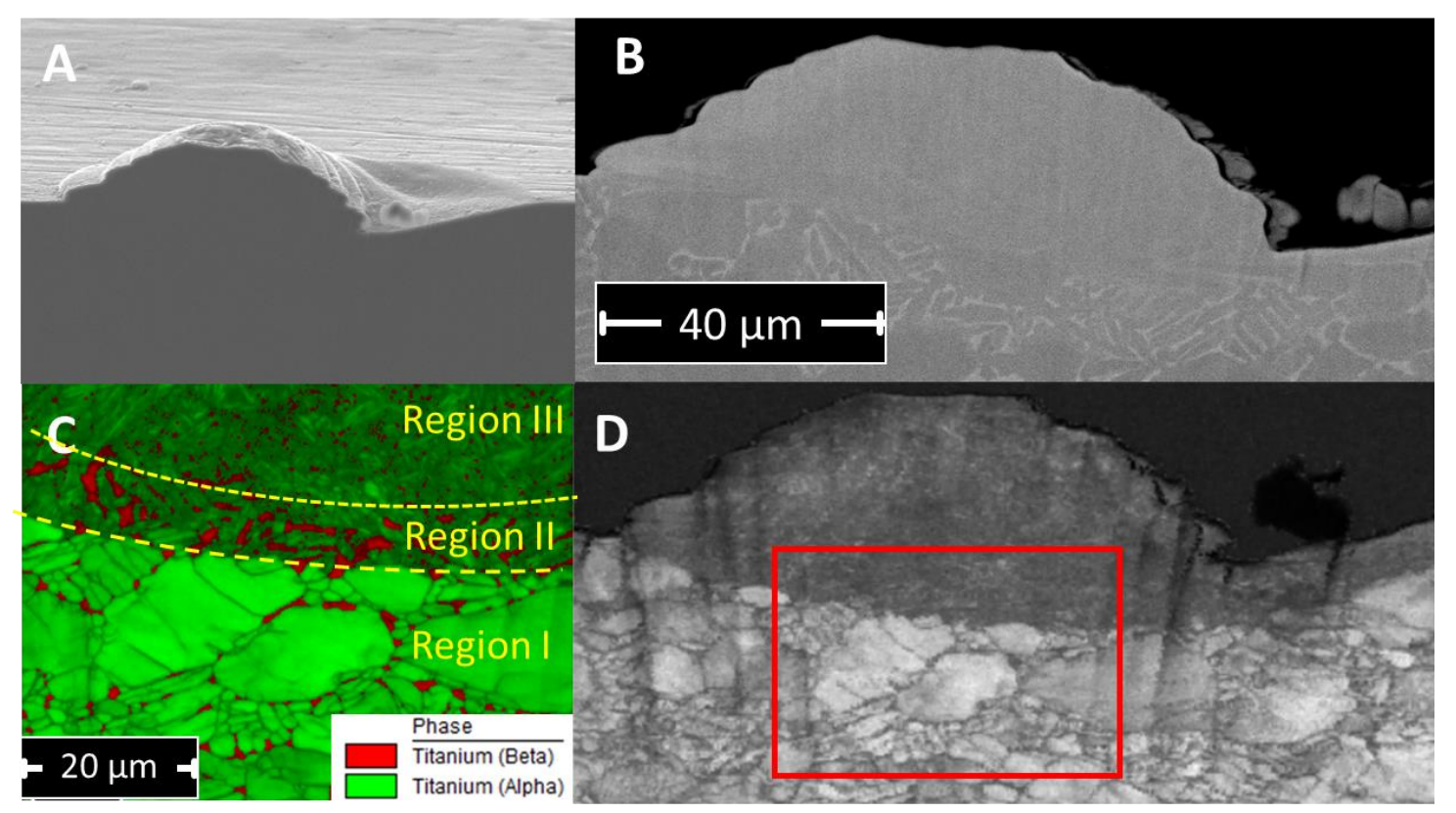

Figure 3. A: Overview of the EDM single crater cross section by SE imaging. B: BSE image of cross section. C: Detailed EBSD phase+quality map. D: Overview EBSD Quality map, red region analyzed in C

BSE image of the crater, presented at Figure $3 \mathrm{~B}$, shows that the bulk material has a bimodal microstructure, i.e., lamellae and globular grains. Lamellae are a mixture of titanium $\alpha$ (darker) and $\beta$ (brighter) phases, obtained after cooling from the $\beta$-field to the room temperature. Note that the globular grains found in the bulk material region are composed entirely of $\alpha$-phase. The observed microstructure, around the globular grains, is comparable to the structure expected after homogenization heat treatment in the $\beta$-field, which promotes a lamellar microstructure, followed by a recrystallization step, leading to the generation of equiaxed and isolated $\alpha$-grains (Lütjering, 1998).

Still in Figure $3 \mathrm{~B}$, the $\alpha+\beta$ lamellar microstructure cannot be observed in the upper regions surrounding the eroded zone. This is an evidence that the microstructure in that region has changed because the material is thermally affected during the process. EBSD is employed for a better evaluation of the microstructural modifications with respect to cooling rate, diffusion effects and highest temperature of this region. In Figure $3 \mathrm{C}$, it is possible to identify three regions. Region I, presents the original bimodal microstructure containing primarily globular $\alpha$-grains. This suggests that temperatures in that zone stayed below the $\alpha-\beta$ transformation temperature, i.e. below $995^{\circ} \mathrm{C}$. Region II shows a mix of $\alpha$ and $\beta$ grains in a lamellar microstructure, which is expected since the material rapidly cooled down from the $\beta$ field and is not subjected to any further recrystallization step. The process employs very high heating rates (Belhadj et al., 2002), which in turn elevate the $\alpha-\beta$ transformation temperature. The vast majority of region III appears to be composed by $\alpha$ phase, but it is most likely $\alpha$ 'martensite. The martensite start temperature for this alloy is $575^{\circ} \mathrm{C}$ and its formation happens for cooling rates larger than $410 \mathrm{~K} / \mathrm{s}$ (Ahmed and Rack, 1998), (Ahmed and Rack, 1998), and both criteria are more than satisfied during EDM. The differentiation of $\alpha$ and martensite phases among region I (globular grains) and regions II and III (lamellar grains) by means of EBSD is difficult because both $\alpha$ and $\alpha^{\prime}$ martensite possess nearly identical crystal structures with hexagonal symmetry.

Multiple craters surfaces are seen in Figure 4. The overview seen in Figure 4 A shows the formation of cracks, which are more common in low ductile phases, such as carbides. The darker BSE signal indicates the presence of a lighter element, likely Carbon. After all, the material was in contact with the hydrocarbon oil used as dielectric in the EDM process at very high temperatures. Voids between phases, seen in the surface of the Figure 4 A, can be an 
evidence of the thermal expansion coefficient difference, from the phases found in the crater region and in the bulk material.

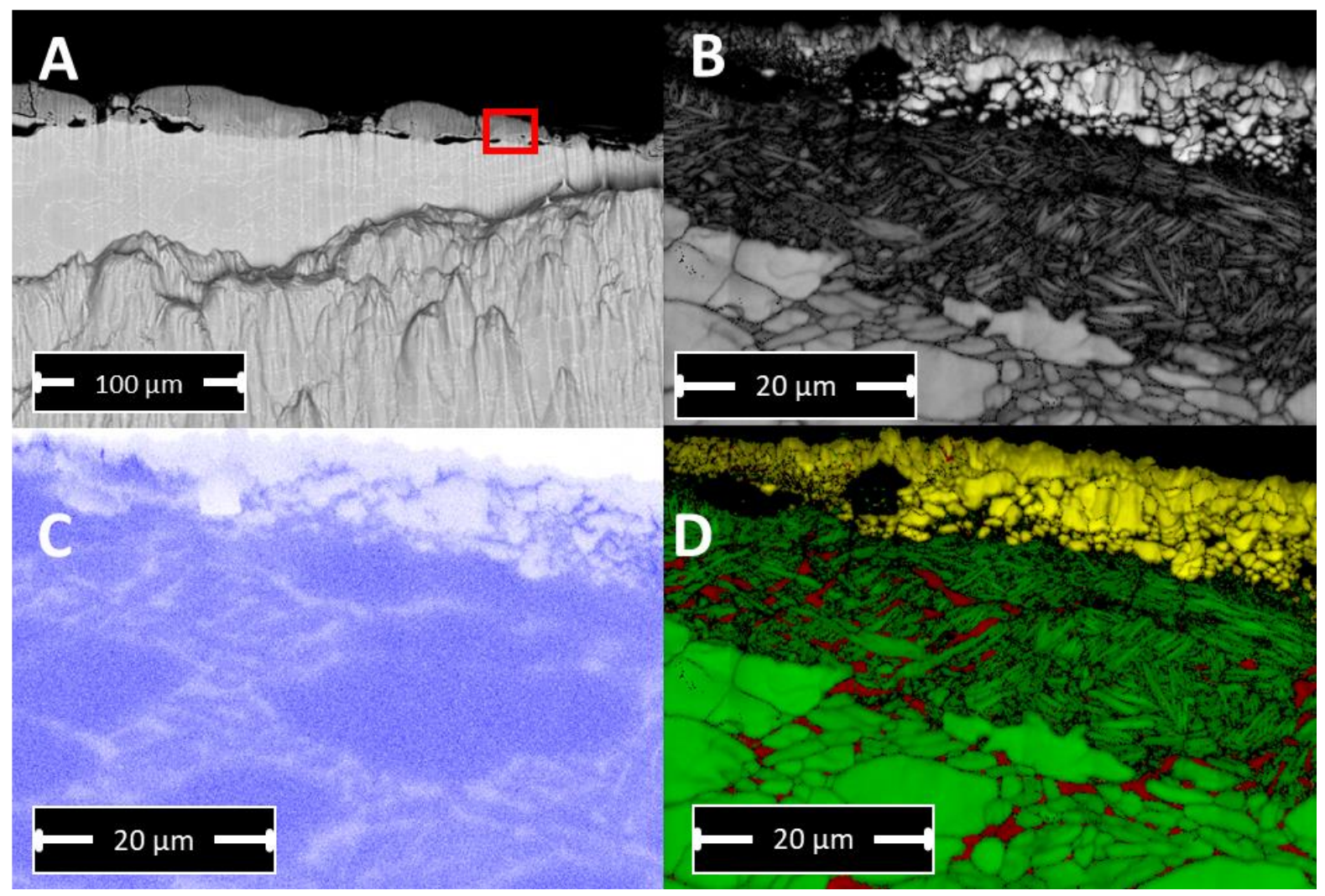

Figure 4. A: Overview of a cross section through the EDM multi crater surface by BSE imaging, red box analysis in B,

C and D. B: EBSD Quality map. C: EDX Aluminum map D: EBSD phase map, green- $\alpha$, red- $\beta$, yellow-carbides

Figure $4 \mathrm{D}$ shows in detail the three different zones already described for the single crater, plus one additional region, a carbide layer (yellow). The Aluminum map of this region (Figure $2 \mathrm{C}$ ) show aluminum-rich zones with shapes similar to the original globular grain structures in areas below the carbide layer, where Figure 2 B shows the presence of a fully lamellar microstructure. This happens because $\alpha$-phase solubilizes low amounts of Al, which is an $\alpha$-stabilizer element. Consequently, the original globular grains contain enough aluminum to destabilize $\beta$-phase, generating regions, which are fully composed of $\alpha$-lamellae, after EDM. It can be observed that the material achieves temperatures in the $\beta$-field (lamellae structure in Figure $4 \mathrm{D}$ ), but the material cooling rate is exceptionally big (around $10^{6} \mathrm{~K} / \mathrm{s}$ ) (Davim, 2008,Liebermann and Walter, 1981) and the diffusion is not noticeable in this region. The lamellae are likely $\alpha$ 'martensite, what is not distinguishable here from the $\alpha$-phase, and are formed during rapid cooling by a nondiffusional transformation. Regarding the sizes of the affected zones, the carbide layer is $5.0 \pm 1.5 \mu \mathrm{m}$ thick, with a lamellar region thicker in the single craters $(16.1 \pm 4.7 \mu \mathrm{m})$ than in the multiple crater $(9.9 \pm 2.7 \mu \mathrm{m})$.

The emission spectra of a $32 \mu \mathrm{s}$ discharge is seen in Figure 5. Even though many characteristic lines of metals (Ti, $\mathrm{Al}, \mathrm{Cu}$ ) are visually dominant in the spectra, the plasma has a high amount of carbon and hydrogen, which can be calculated with plasma simulation as shown by (Wiessner et al., 2018). Prominent peaks originating from the dielectric elements can be observed at high spectra resolution with $\mathrm{H}_{\alpha}$ at $656.28 \mathrm{~nm}, \mathrm{C}$ I at $658.8 \mathrm{~nm}$ and C II at $658.3 \mathrm{~nm}$. Those components are originated from cracking of highly linked hydrocarbons into their element species. Free carbon ions and atoms can recombine with titanium and form the carbides. The formation of $\mathrm{TiC}$ in plasma is know and can be used for coating (Delplancke-Ogletree and Monteiro, 1997). Unfortunately TiC has a high tendency to form micro cracks which can be also observed in Figure $4 \mathrm{~A}$. 


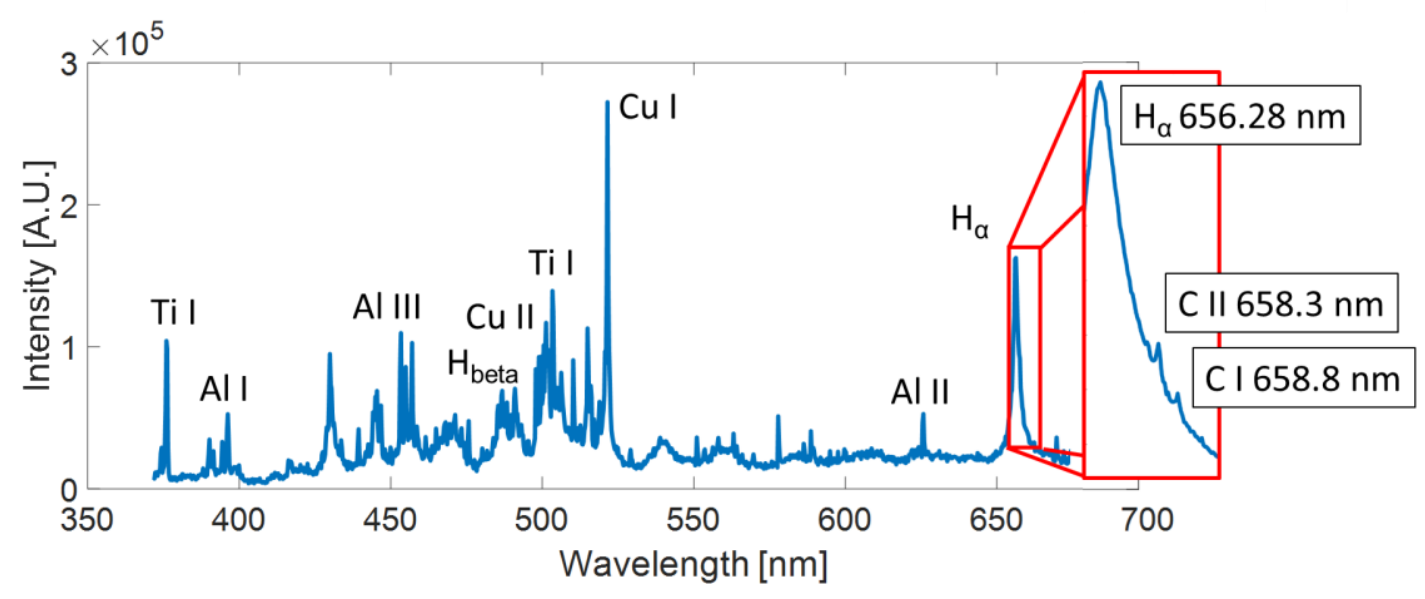

Figure 5. Plasma emission spectra of a $32 \mu$ s discharge with workpiece TI-6AL-4V and tool copper in oil. Red highresolution of $\mathrm{H}_{\alpha}$ with overlapping carbon peaks

\section{SUMMARY}

The different melting and phase transition points of the materials can be used to estimate temperatures reached in the EDM process, schematically summarized in Figure 6. The titanium overtake its allotropic transformation $\left(995^{\circ} \mathrm{C}\right)$ and melting $\left(1660^{\circ} \mathrm{C}\right)$ temperatures (Hasçalık and Çaydaş, 2007). The spark duration of $32 \mu \mathrm{s}$ and the melt point of Titanium estimates a heating rate of $5 \cdot 10^{6} \mathrm{~K} / \mathrm{s}$ in the outer rim to the carbide layer. The carbide layer itself has a melting point of $3150^{\circ} \mathrm{C}$ so heating rates of $10^{7} \mathrm{~K} / \mathrm{s}$ are likely. The anode respectively cathode spot region reaching usually temperatures 3'000 K to 5'000 K (Descoeudres, 2006). The plasma above reaches much higher temperatures, plasma simulations estimates temperatures higher than $10^{\prime} 000 \mathrm{~K}$, also visible by strong ALIII peaks.

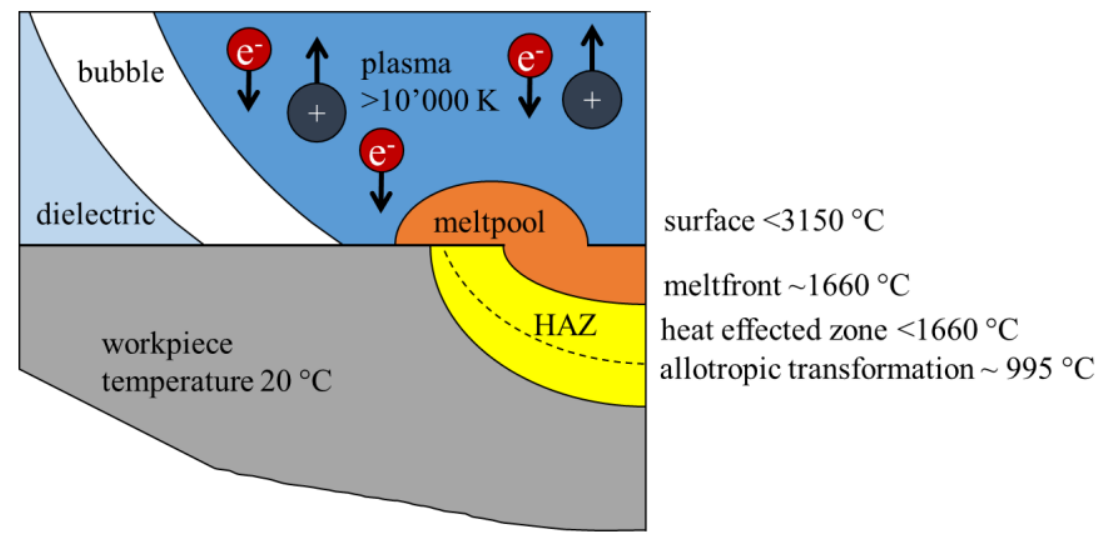

Figure 6. Schematic of the different EDM temperature region, representative for erosion of titanium (positive workpiece electrode)

The formation of the carbide layer on positive polarized workpieces has its major origin in the titanium debris from previous discharges, which, transform to titanium carbide and attach to the positive workpiece surface. Even though carbon could diffuse from the EDM plasma into the melt pool, the formation of TiC due to diffusion is unlikely, especially since ionized carbon tend to move to the negative electrode. A single discharge has no significant carbide layer, only some ripples can be observed which may form during the bubble collapse. Research with titanium powder in oil dielectric were performed by (Furutani et al., 2009). The formation of a TiC layer on a steel workpiece is observed by eroding with a copper tool (negative). All those observations indicate that $\mathrm{TiC}$ layer formation might have its primary source from the debris suspended in the dielectric originated from the previous sparks, which accumulate with each next spark.

\section{REFERENCES}

Ahmed, T. and Rack, H., 1998. Phase transformations during cooling in $\alpha+\beta$ titanium alloys. Materials Science and Engineering: A, 243, 206-211.

Belhadj, A., Baudouin, P. and Houbaert, Y., 2002. Simulation of the HAZ and magnetic properties of laser cut nonoriented electrical steels. Journal of magnetism and magnetic materials, 248, 34-44. 
Caggiano, A., Teti, R., Perez, R. and Xirouchakis, P., 2015. Wire EDM Monitoring for Zero-Defect Manufacturing based on Advanced Sensor Signal Processing. Procedia CIRP, 33, 315-320.

Davim, J. P., 2008: Machining: fundamentals and recent advances. Springer Science \& Business Media.

Delplancke-Ogletree, M.-P. and Monteiro, O. R., 1997. Deposition of titanium carbide films from mixed carbon and titanium plasma streams. Journal of Vacuum Science \& Technology A: Vacuum, Surfaces, and Films, 15, 1943-1950.

Descoeudres, A., 2006: Characterization of electrical discharge machining plasmas. EPFL.

Furutani, K., Sato, H. and Suzuki, M., 2009. Influence of electrical conditions on performance of electrical discharge machining with powder suspended in working oil for titanium carbide deposition process. The International Journal of Advanced Manufacturing Technology, 40, 1093-1101.

Hasçalık, A. and Çaydaş, U., 2007. Electrical discharge machining of titanium alloy (Ti-6Al-4V). Applied Surface Science, 253, 9007-9016.

Holsten, M., Koshy, P., Klink, A. and Schwedt, A., 2018. Anomalous influence of polarity in sink EDM of titanium alloys. CIRP Annals, 67, 221-224.

Klocke, F., Schneider, S., Ehle, L., Meyer, H., Hensgen, L. and Klink, A., 2016. Investigations on Surface Integrity of Heat Treated 42CrMo4 (AISI 4140) Processed by Sinking EDM. Procedia CIRP, 42, 580-585.

Liebermann, H. and Walter, J., 1981. Rapid solidification of metastable materials. MRS Online Proceedings Library Archive, 8.

Lütjering, G., 1998. Influence of processing on microstructure and mechanical properties of $(\alpha+\beta)$ titanium alloys. Materials Science and Engineering: A, 243, 32-45.

Macedo, F. T. B., 2018: Fundamental Investigation of Dry EDM Plasmas. ETH Zurich.

Wiessner, M., Macedo, F. T., Martendal, C., Kuster, F. and Wegener, K., Fundamental investigation of EDM plasmas, part I: a comparison between electric discharges in gaseous and liquid dielectric media. in Proceedings of the Proceedings of the 19th ISEM Conference (ISEM-XIX), 2018, p. 330-335.

\section{ACKNOWLEDGMENTS}

We would like to thank Dr. Christoph Hollenstein for his great collaboration.

\section{RESPONSIBILITY NOTICE}

The author(s) is (are) the only responsible for the printed material included in this paper. 